\title{
Bacterial community structure in the Bohai Strait provides insights into organic matter niche partitioning
}

\author{
Yibo Wang ${ }^{\mathrm{a}, \mathrm{b}, \mathrm{c}}$, Bin Wang ${ }^{\mathrm{a}, \mathrm{b}, \mathrm{c}}$, Lisa M. Dann ${ }^{\mathrm{d}}$, James G. Mitchell ${ }^{\mathrm{d}}$, Xiaoke Hu${ }^{\mathrm{a}, \mathrm{b}, *}$, Haitian Tang ${ }^{\mathrm{e}}$, \\ Hua Zhang ${ }^{f}$, Yanqing Sheng ${ }^{g}$ \\ ${ }^{a}$ Key Laboratory of Coastal Biology and Bioresource Utilization, Yantai Institute of Coastal Zone Research, Chinese Academy of Sciences, Yantai 264003, China \\ ${ }^{\mathrm{b}}$ Laboratory for Marine Biology and Biotechnology, Qingdao National Laboratory for Marine Science and Technology, Qingdao 266237, China \\ ${ }^{\mathrm{c}}$ University of Chinese Academy of Sciences, Beijing 100049, China \\ ${ }^{\mathrm{d}}$ School of Biological Sciences, Flinders University, Adelaide 5042, Australia \\ e Yantai Monitoring Center of Marine Environment, State Oceanic Administration People's Republic of China, Yantai 264003, China \\ ${ }^{\mathrm{f}}$ Key Laboratory of Coastal Zone Environmental Processes and Ecological Remediation, Yantai Institute of Coastal Zone Research, Chinese Academy of Sciences, Yantai \\ 264003, China \\ ${ }^{\mathrm{g}}$ Research Center for Coastal Environment Engineering Technology of Shandong Province, Yantai Institute of Coastal Zone Research, Chinese Academy of Sciences, Yantai \\ 264003, China
}

\section{A R T I C L E I N F O}

\section{Keywords:}

Bohai Strait

Bacterial community

Seasonal and spatial heterogeneity

Environmental factor

Organic matter

Hydrodynamics

Niche partitioning

\begin{abstract}
A B S T R A C T
The Bohai Strait is a crucial pathway for water exchange between the Bohai Sea and the Yellow Sea, and exhibits a robust spatiotemporal pattern of hydrodynamic conditions. 16S rRNA amplicon sequencing was applied to study the spatiotemporal patterns of bacterial community composition and diversity in the Bohai Strait. Physical and chemical parameters were measured in order to explain what might control the observed patterns in community composition and diversity. In response to environmental changes between seasons, especially the dramatic changes of temperature and nutrient $\left(\mathrm{NO}_{2}-\mathrm{N}\right.$ and $\left.\mathrm{PO}_{4}-\mathrm{P}\right)$ levels, Synechococcus and unclassified genera in Family I predominated in summer while some oligotrophic taxa (e.g., Pelagibacter, OM43 clade) are more abundant in winter. The spatial heterogeneity and overall patchiness of bacterial assemblages in the Bohai Strait could not be well explained by the measured factors. However, the taxa with the most spatially variable presence and absence, e.g. Vibrionaceae, SAR11 and Sva0996 marine group, possess differentiated niches for utilization of organic matter (OM) and display a close relationship with the distribution of OM sources in this area, which may indicate the significance of OM sources to bacterial community structure. Our results suggest that local factors rather than regional factors, such as dispersal limited by hydrodynamics, structure the bacterial communities in the Bohai Strait.
\end{abstract}

\section{Introduction}

Marine bacteria are crucial in the functioning of the global ocean ecosystem due to their key roles in marine biogeochemical cycling of the major elements (Fuhrman et al., 2015; Bunse and Pinhassi, 2017). They can have fast growth rates and remarkable capabilities to respond to physicochemical gradients and environmental changes (both natural and anthropogenic), resulting in specific spatial and temporal patterns (Lindh et al., 2015; Bunse and Pinhassi, 2017). Bacteria in surface oceans exhibit pronounced seasonal patterns, which are governed by different factors (e.g., light, climate, and nutrient loading) at different temporal scales (Lindh et al., 2015; Bunse and Pinhassi, 2017). Further, several studies on microbial biogeography suggest that both regional and local forces have an important role in structuring bacterial communities in marine environments, though their relative importance depends on the spatial scale and environmental heterogeneity (Martiny et al., 2006; Lindström and Langenheder, 2012; Lindh et al., 2017). To clarify the spatiotemporal patterns of bacterial communities, as well as their relation to environmental changes, would provide insights into the relationship between microbial-mediated processes and environmental factors.

The Bohai Strait (BS) is the only pathway connecting the Bohai Sea and the Yellow Sea in China (Fig. 1). This area is crucial to the water and material exchange between the Bohai Sea and the open ocean $(\mathrm{Bi}$

\footnotetext{
* Corresponding author at: Key Laboratory of Coastal Biology and Bioresource Utilization, Yantai Institute of Coastal Zone Research, Chinese Academy of Sciences, Yantai 264003, China.

E-mail address: xkhu@yic.ac.cn (X. Hu).
} 


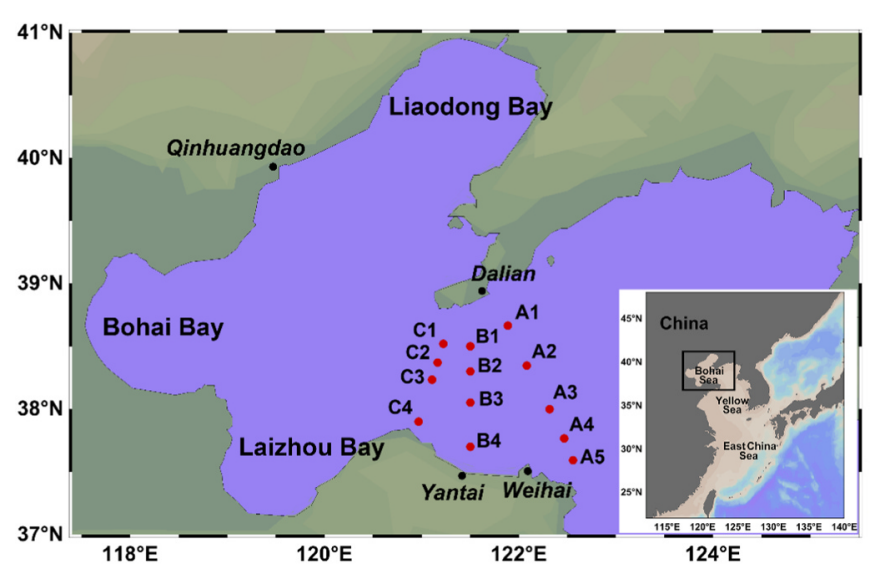

Fig. 1. Location of sampling sites in the Bohai Strait.

et al., 2011; Li et al., 2015). The strait is roughly divided into two parts by North Huangcheng Island. The northern BS is narrow and deep (maximum depth $\sim 75 \mathrm{~m}$ ), and the southern BS is much wider but shallow (depth typically less than $20 \mathrm{~m}$ ) (Li et al., 2015). Oceanic water enters the Bohai Sea from the Yellow Sea through the northern BS, while less saline coastal water flows out to the Yellow Sea through the southern strait (Fang et al., 2000; Cheng et al., 2004; Li et al., 2015). The Bohai circulation and the Yellow Sea Warm Current (YSWC) are affected by the seasonal variation of the East Asia Monsoon and exhibit robust seasonal variations, and consequently, the seasonal pattern of the hydrodynamics in the Bohai Strait is striking, especially between summer and winter (Chen, 2009; Bi et al., 2011; Liu et al. 2015) (Fig. S1, Supporting Information). In winter, the warmer, more saline and nutrient-poor Yellow Sea Warm Current (YSWC) enters the northern BS, while colder, fresher and nutrient-rich Bohai Sea Coastal Water (BSCW) occupies the southern BS (Fang et al., 2000; Hainbucher et al., 2004; Chen, 2009; Bi et al., 2011) (Fig. S1, Supporting Information). In contrast, the hydrodynamics in summer are relatively weak, and the differences in temperature and salinity between the northern and southern strait become less evident (Fig. S1, Supporting Information). In addition to natural hydrodynamic forces, this area is also experiencing anthropogenic impacts. There are a number of important ports and agricultural areas centered around the cities of Dalian, Yantai and Weihai, on both sides of the Bohai Strait (Fig. 1). As a result of both hydrodynamic and anthropogenic impacts, environmental gradients in the Bohai Strait have a broad range, and the microbial communities are thought to show great heterogeneity in response to these environmental forces. Previous studies in the Bohai Strait have largely focused on the physical processes (Cheng et al., 2004; Li et al., 2015; Bi et al., 2011; Guo et al., 2016), whereas relatively little is known about the biotic communities and their response to environmental changes (Wang et al., 2016).

In this study, we investigated the bacterial communities in the surface waters of the Bohai Strait using $16 \mathrm{~S}$ rRNA amplicon sequencing. The aims of this study were (1) to elucidate the spatiotemporal occurrence patterns and diversities of the bacterial assemblages in the Bohai Strait and (2) to illuminate how the bacterial assemblages respond to environmental changes. From these, we expect a better understanding of the driving forces and mechanisms of the bacterial community pattern in such a complex coastal environment.

\section{Materials and methods}

\subsection{Study sites and sampling}

Sampling was conducted at 13 sites along transects A, B and C (Fig. 1), which were nearly perpendicular to the direction of the current. In December 2013 and August 2014, surface seawater samples were collected using Niskin bottles attached to a CTD rosette. Temperature (T), salinity (Sal) and bottom depth (Depth) were measured by the CTD. Chlorophyll $a$ ( $\mathrm{Chl} a$ ) fluorescence was measured with a WET Labs ECO-AFL/FL fluorometer sensor. Chemical parameters, i.e. nitrate $\left(\mathrm{NO}_{3}-\mathrm{N}\right)$, nitrite $\left(\mathrm{NO}_{2}-\mathrm{N}\right)$, ammonium $\left(\mathrm{NH}_{4}-\mathrm{N}\right)$, phosphate $\left(\mathrm{PO}_{4}-\mathrm{P}\right)$, silicate $\left(\mathrm{SiO}_{3}-\mathrm{Si}\right)$ were measured as previously described by Wang et al. (2016).

For bacterial diversity analysis, $2 \mathrm{~L}$ of surface seawater from each site was filtered through a $0.22 \mu \mathrm{m}$ filter $(47 \mathrm{~mm}$, Millipore Corporation). The filters were then immediately placed into sterile cryovials and stored at $-80^{\circ} \mathrm{C}$ for subsequent DNA extraction.

\subsection{DNA extraction and Illumina MiSeq sequencing}

Total genomic DNA was extracted from each of the filtered water samples using a PowerSoil DNA Isolation Kit (MoBio, Carlsbad, CA, USA), according to the manufacturer's instructions. DNA concentration and quality were measured using a NanoDrop ND-2000c Spectrophotometer (Thermo Scientific, Inc., USA). Extracted DNA was

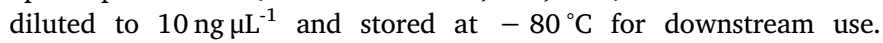
Universal primers 515 F (5'-GTGCCAGCMGCCGCGGTAA-3') and 909 R (5'-CCCCGYCAATTCMTTTRAGT-3') with $12 \mathrm{nt}$ unique barcode at 5'end of $515 \mathrm{~F}$ was used to amplify the V4-V5 hypervariable region of $16 \mathrm{~S}$ rRNA gene. All PCR products were quantified with a NanoDrop spectrophotometer and then pooled together with equal molar amount from each sample. The sample used for sequencing was prepared using TruSeq DNA kit according to the manufacture's instruction. The purified library was diluted, denatured, re-diluted, mixed with PhiX (equal to $30 \%$ of final DNA amount) as described in the Illumina library preparation protocols, and then was sequenced on Illumina Miseq system for sequencing with the Reagent Kit v2 $2 \times 250 \mathrm{bp}$ at the Environmental Genome Platform of Chengdu Institute of Biology.

\subsection{Bioinformatic analysis}

The sequence data were processed using Mothur v.1.36.1 (Schloss et al., 2009). All sequence reads were trimmed and assigned to each sample based on their barcodes. Sequences with lengths $>260 \mathrm{bp}$, without ambiguous bases, and average base quality scores $>25$ were used for downstream analysis. The aligned $16 \mathrm{~S}$ rRNA gene sequences were checked for chimeric sequences using the UCHIME algorithm (Edgar et al., 2011). Sequences were clustered into operational taxonomic units (OTUs) using the average neighbor algorithm in MOTHUR at a $97 \%$ identity threshold. Each OTU contained more than two sequences from at least two samples to avoid errors or PCR artifacts (Zhou et al., 2011).

\subsection{Statistical analysis}

Alpha diversities (observed species, Chao1, Shannon diversity, Shannon evenness and Good's coverage) were calculated at the OTU level using Mothur v.1.34.4 with each sample randomly subsampled to the same number of sequences as the sample with the lowest sequences. The differences of alpha-diversity indices between samples were tested by student's $t$-test using SPSS v.18.0 (SPSS inc., Chicago, USA).

Beta-diversity analyses were conducted at the genus level (including the sequences identified to the family level and unclassified at the genus level). Differences between samples were explored using non-metric multidimensional scaling (nMDS). The global and pairwise differences among sets of samples were tested by analysis of similarity (ANOSIM, 999 permutations). Clustered heatmaps were constructed to display the relative abundances (RAs) of genera and hierarchical clustering of samples. The aforementioned beta-diversity analyses were performed based on the Bray-Curtis similarity matrices calculated from community data using vegan v.2.3-3 and ggplot2 v.2.2.0 packages in $R$ ( $R$ Core Team, 2015). 
The differences between two groups of samples were compared with the Mann-Whitney $U$ test. Environmental variables that had the highest Spearman correlation coefficients with bacterial communities were detected using the biota-environment (BIOENV). Networks were generated to visualize the relationship between bacteria and environmental factors. Spearman correlation coefficient $\mathrm{r}$ values and $P$-values were calculated for pairs of one genus to one environmental factor pair by the 'psych' package in R software. $P$-values were corrected by implementing false discovery rates (q-values) that was were kept below $5 \%$ with the Benjamini Hochberg procedure (Benjamini and Hochberg, 1995). Significant pairwise correlations (edges) between most abundant bacterial genera (the cumulative percentage of sequences was no less than $90 \%$ ) and environmental parameters ( $\mathrm{r}<-0.6$ or $>0.6$ ) were visualized using the edge-weighted spring embedded model with the Cytoscape v.3.3.0 (Shannon, 2003). The bacterial 16 S rRNA gene sequences derived from pyrosequencing were deposited in the NCBI Sequence Read Archive database under accession no. SRP082148.

\section{Results}

\subsection{Physicochemical characteristics of surface waters}

In winter, the temperature and salinity of surface waters were significantly higher in the northern and middle BS than in the southern part (Fig. S2, Supporting Information). The temperature was much higher in summer $\left(24.3^{\circ} \mathrm{C}\right)$ compared with winter $\left(8.7^{\circ} \mathrm{C}\right)$, while the salinity changed little (summer: 30.6 ; winter: 30.8 ) and the maximum values (summer: $31.1 \mathrm{psu}$; winter: $31.4 \mathrm{psu}$ ) were both recorded in the northeastern section. However, both parameters appeared to be more evenly distributed in summer due to the weak hydrodynamics (Table 1, Fig. S2, Supporting Information). The concentrations of inorganic nutrients in winter showed remarkable differences between the western and eastern parts of the study area (Fig. S2, Supporting Information). The concentrations of $\mathrm{NO}_{2}-\mathrm{N}, \mathrm{NO}_{3}-\mathrm{N}, \mathrm{NH}_{4}-\mathrm{N}$, and $\mathrm{SiO}_{3}-\mathrm{Si}$ were higher in the west than in the east, while the content of $\mathrm{PO}_{4}-\mathrm{P}$ displayed the opposite trend (Fig. S2, Supporting Information). In summer, the concentrations of all 5 nutrients were much lower than in winter, especially $\mathrm{NO}_{2}-\mathrm{N}$, which decreased by $\sim 12$ times (Table 1 ). $\mathrm{PO}_{4}-\mathrm{P}$ showed a similar distribution trend with temperature and salinity as in winter, while the other nutrients $\left(\mathrm{NO}_{2}-\mathrm{N}, \mathrm{NO}_{3}-\mathrm{N}, \mathrm{NH}_{4}-\mathrm{N}, \mathrm{SiO}_{3}-\mathrm{Si}\right)$ showed different distributions (Fig. S2, Supporting Information).

\subsection{Taxonomic composition and diversity of bacterial communities}

After filtering and removing potential erroneous sequences, a total of 931,759 bacterial $16 \mathrm{~S}$ rRNA gene sequences were retrieved from 26 surface sample libraries. Removal of singletons resulted in 736,083 effective sequences for further analysis. After random resampling, a total of 16,112 operational taxonomic units (OTUs) were obtained at $97 \%$ sequence identity. The coverages of all samples were higher than $85 \%$, indicating that the surveying results were sufficient to capture the

Table 1

Statistical information of environmental parameters in the Bohai Strait.

\begin{tabular}{|c|c|c|c|c|c|c|}
\hline \multirow{2}{*}{$\begin{array}{l}\text { Environmental } \\
\text { parameters }\end{array}$} & \multicolumn{3}{|l|}{ Winter } & \multicolumn{3}{|l|}{ Summer } \\
\hline & Range & Mean & SD & Range & Mean & $\mathrm{SD}$ \\
\hline Water depth (m) & $19.80-60.00$ & 41.74 & 14.22 & $19.80-56.00$ & 41.15 & 13.55 \\
\hline Temperature $\left({ }^{\circ} \mathrm{C}\right)$ & $6.20-9.95$ & 8.67 & 1.21 & $22.74-25.98$ & 24.32 & 0.92 \\
\hline Salinity (psu) & $28.43-31.39$ & 30.81 & 0.85 & $30.25-31.11$ & 30.60 & 0.25 \\
\hline $\mathrm{NO}_{2}-\mathrm{N}\left(\mu \mathrm{g} \mathrm{L}^{-1}\right)$ & $4.09-16.24$ & 8.56 & 3.50 & $0.44-1.20$ & 0.74 & 0.24 \\
\hline $\mathrm{NO}_{3}-\mathrm{N}\left(\mu \mathrm{g} \mathrm{L}^{-1}\right)$ & $1.03-167.15$ & 77.03 & 47.86 & $9.90-51.40$ & 30.84 & 14.15 \\
\hline $\mathrm{NH}_{4}-\mathrm{N}\left(\mu \mathrm{L} \mathrm{L}^{-1}\right)$ & $3.90-135.86$ & 45.13 & 45.01 & $0.50-37.70$ & 12.89 & 9.42 \\
\hline $\mathrm{PO}_{4}-\mathrm{P}\left(\mu \mathrm{g} \mathrm{L}^{-1}\right)$ & $2.03-10.37$ & 6.45 & 2.82 & $0.67-6.99$ & 2.50 & 1.72 \\
\hline $\mathrm{SiO}_{3}-\mathrm{Si}\left(\mathrm{mg} \mathrm{L}^{-1}\right)$ & $0.14-0.43$ & 0.28 & 0.10 & $0.08-0.25$ & 0.17 & 0.05 \\
\hline Chl $a\left(\mu \mathrm{L} \mathrm{L}^{-1}\right)$ & $0.22-1.09$ & 0.56 & 0.28 & $0.14-6.16$ & 1.47 & 1.67 \\
\hline
\end{tabular}

Table 2

Analysis of similarity (ANOSIM) statistics testing the differences of bacterial community composition (at the genus level) based on Bray-Curtis similarity matrices.

\begin{tabular}{|c|c|c|c|c|}
\hline \multicolumn{3}{|c|}{ Grouping by } & \multicolumn{2}{|l|}{ Statistics } \\
\hline & & & \multirow{2}{*}{$\begin{array}{l}R \\
0.7849\end{array}$} & \multirow{2}{*}{$\begin{array}{l}P \\
0.001\end{array}$} \\
\hline Season & & & & \\
\hline \multirow[t]{9}{*}{ Transect } & Winter & global & 0.362 & 0.005 \\
\hline & & $A \& B$ & 0.588 & 0.019 \\
\hline & & B \& C & 0.490 & 0.050 \\
\hline & & A \& C & -0.031 & 0.575 \\
\hline & Summer & global & 0.359 & 0.005 \\
\hline & & $A \& B$ & 0.388 & 0.016 \\
\hline & & B \& C & 0.313 & 0.145 \\
\hline & & A \& C & 0.413 & 0.035 \\
\hline & & B1, B2 \& Others & 0.882 & 0.016 \\
\hline
\end{tabular}

$F, F$-statistic; $P, P$-values. Significant $P$-values $(<0.05)$ are highlighted in bold.

overall bacterial diversities (Table $\mathrm{S} 1$ ). All sequences were affiliated to 44 phyla, 122 classes, 223 orders, 388 families and 744 genera (including sequences unclassified at each taxonomy) with confidence score thresholds of $80 \%$. Of all sequences, $87.5 \%$ and $56.2 \%$ could be identified to the family and the genus level, respectively.

\subsection{The seasonal shift of bacterial communities}

ANOSIM results suggested a significant difference of bacterial community composition between summer and winter (Table 2). Likewise, the nMDS plot showed a clear division between the samples from the two seasons (Fig. 2). Non-parametric Mann-Whitney $U$ test resulted in 10 highly responsive taxa, the RAs of which were more than $1 \%$ and varied dramatically between seasons $(P<0.05$; Fig. 3). Synechococcus and unclassified genera in Family I dominated the bacterial communities in summer $(17.5 \%$ and $11.0 \%$, respectively), but their RAs decreased sharply in winter (3.85\% and $1.7 \%$, respectively) (Fig. 3). Meanwhile, the unclassified genera (Vibrionaceae) were also more abundant in summer. While in winter, the oligotrophic bacterial taxa were more abundant compared to their RAs in summer (Fig. 3), i.e. Pelagibacter (winter: $12.19 \%$, summer: $5.83 \%$ ), OM43 clade (winter: $3.19 \%$, summer: $1.55 \%$ ), unclassified genera of SAR86 clade (winter: $3.13 \%$, summer: $1.66 \%$ ), and unclassified genera of Surface 2 (winter: $2.22 \%$, summer: $1.21 \%$ ). Further, RAs of Planctomyces (2.13\% in winter and $0.49 \%$ in summer) markedly increased in winter (Fig. 3). The alpha diversity indices of bacterial communities (total OTUs) were compared between seasons and significant variations were observed in richness,

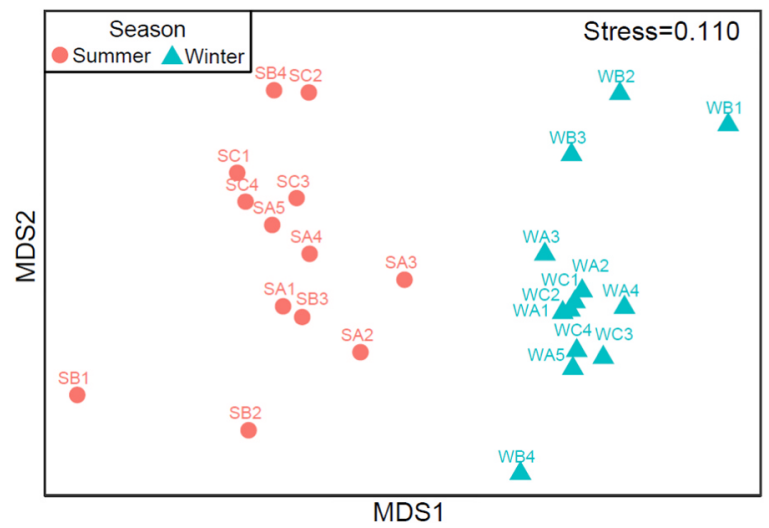

Fig. 2. Non-metric multidimensional scaling (nMDS) plot showing the bacterial community structure across different seasons based on the Bray-Curtis dissimilarity distance matrices of genus data. Each sample label includes the information of season (W: winter; S: summer) and site ID (e.g. A1, A2, etc). 


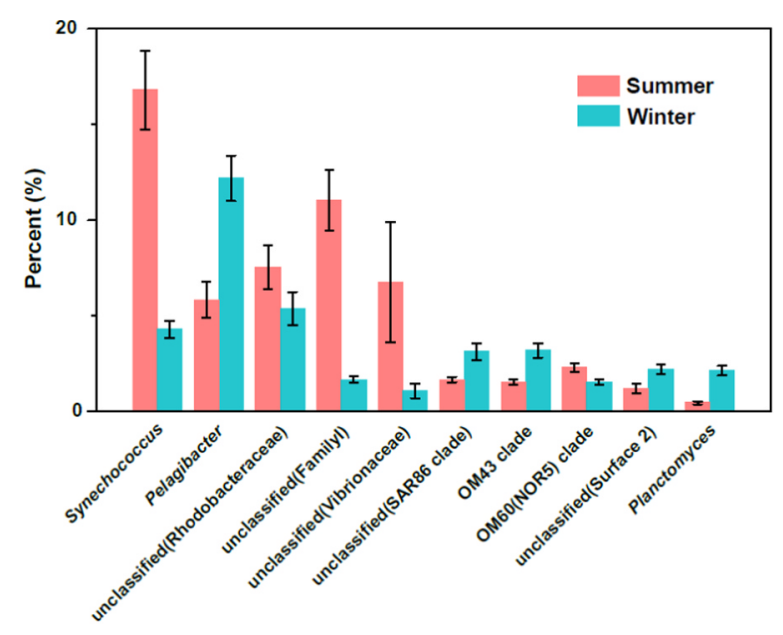

Fig. 3. Bar plot showing the relative abundances of the genera with significant variations (Kruskal-Wallis test, $P<0.05$ ) between seasons.

diversity and evenness, which were higher in winter than in summer $(t$ test: $P<0.05$; Table 3). And the differences in Shannon diversity and evenness were even more statistically significant ( $t$-test: $P<0.01$; Table 3).

\subsection{The spatial pattern of bacterial communities}

In each season, bacterial community composition varied spatially (Table 2, Fig. 4). In winter, the community composition of transect B was found to be significantly different from those of transects $A$ and $C$ in winter $(P<0.05$, Table 2, Figs. 4B \& 5B), while sites B1 and B2 had a distinct community composition from other regions in summer $(P<0.05$, Table 2, Figs. 4A \& 5A). In terms of the highly responsive taxa to the spatial environmental changes, transect $B$ was distinct in winter for containing more unclassified genera in Sva0996 marine group but fewer Pelagibacter and unclassified genera in SAR86, Surface 2, Family I and NS9 marine group (Fig. 5B, D). Sites B1 and B2 were distinct in summer due to the abundance of unclassified genera within Vibrionaceae and a lower abundance of Family I (Fig. 5A, C). Alpha diversity indices of bacterial communities at the OTU level (97\% identity) were tested between transects. The diversity or evenness of transect B were lower than transects A and C in summer (ANOVA: $P<0.05$ ), but no significant difference was observed among transects in winter (Table 3).

\subsection{Environmental determinants of seasonal variation of bacterial communities}

A total of 9 local environmental factors (physical factors: T, Sal, Depth; chemical factors: $\mathrm{NO}_{2}-\mathrm{N}, \mathrm{NO}_{3}-\mathrm{N}, \mathrm{NH}_{4}-\mathrm{N}, \mathrm{PO}_{4}-\mathrm{P}, \mathrm{SiO}_{3}-\mathrm{Si}$; biological factors: $\mathrm{Chl} a$ ) were selected to study their relationships with the bacterial communities in the Bohai Strait. Results of BIOENV showed that among them, temperature was the best fit to explain the seasonal variation of bacterial community composition at the genus level ( $R=0.584$; Table S2, Supporting Information). The network focusing on the bacteria-environment interactions related to the seasonal shift, emphasized the impacts of temperature and nutrient levels on the bacterial community pattern and further elucidated the interactions between bacterial genera and environmental factors (Fig. 6). It revealed that among the genera responsive to seasonal changes, Synechococcus and unclassified genera of Family I had strong positive correlations with temperature but negative correlations with different nutrient factors, while Planctomyces showed the opposite trends. OM43 clade had a negative correlation with temperature (Fig. 6).

\subsection{Environmental determinants of spatial heterogeneity of bacterial communities}

BIOENV analysis revealed that among the selected variables, temperature, salinity and $\mathrm{SiO}_{3}$-Si jointly explained the most of community dissimilarity in summer $(R=0.314$; Table $S 3$, Supporting Information), while temperature alone explained most of the community dissimilarity in winter $(R=0.441$; Table S3, Supporting Information). Network analysis showed that among the measured factors, temperature was correlated with the majority of the abundant bacterial genera in both seasons, indicating that it could explain the spatial variation of these genera to some degree (Fig. 7). However, the unclassified genera in Vibrionaceae, which exhibited the most uneven distribution in summer (Fig. 5C), did not show any obvious correlations with the measured

Table 3

$T$-test and Fisher's LSD (ANOVA) statistics testing the seasonal and spatial differences in alpha diversity estimators of the bacterial OTUs from the Bohai Strait.

\begin{tabular}{|c|c|c|c|c|c|c|c|c|c|c|}
\hline \multirow{2}{*}{\multicolumn{3}{|c|}{ Grouping by }} & \multicolumn{2}{|c|}{$\begin{array}{c}\text { Observed } \\
\text { species }\end{array}$} & \multicolumn{2}{|c|}{ Chao1 } & \multicolumn{2}{|c|}{$\boldsymbol{H}^{\prime}$} & \multicolumn{2}{|c|}{$E$} \\
\hline & & & $T / F$ & $P$ & $T / F$ & $P$ & $T / F$ & $P$ & $T / F$ & $P$ \\
\hline \multicolumn{3}{|c|}{ Season } & 3.366 & 0.003 & 2.436 & 0.023 & 6.763 & $<0.001$ & 7.199 & $<0.001$ \\
\hline \multirow{9}{*}{ Region } & & Global & 0.022 & 0.978 & 0.187 & 0.832 & 0.068 & 0.934 & 0.089 & 0.916 \\
\hline & & A \& B & & 0.938 & & 0.610 & & 0.936 & & 0.885 \\
\hline & & $\mathrm{B} \& \mathrm{C}$ & & 0.904 & & 0.600 & & 0.734 & & 0.688 \\
\hline & & $A \& C$ & & 0.837 & & 0.965 & & 0.781 & & 0.780 \\
\hline & \multirow{5}{*}{ Summer } & Global & 1.157 & 0.353 & 0.512 & 0.614 & 3.575 & 0.067 & 4.196 & 0.048 \\
\hline & & A \& B & & 0.180 & & 0.440 & & 0.029 & & 0.024 \\
\hline & & $\mathrm{B} \& \mathrm{C}$ & & 0.734 & & 0.924 & & 0.070 & & 0.900 \\
\hline & & $A \& C$ & & 0.308 & & 0.385 & & 0.689 & & 0.038 \\
\hline & & B1, B2 \& others & 1.086 & 0.301 & 0.898 & 0.389 & 3.316 & 0.007 & 3.822 & 0.003 \\
\hline
\end{tabular}

$H^{\prime}$, Shannon-Weaver diversity; $E$, Shannon-Weaver evenness; $T / F, T$-statistic of the test for seasonal differences or $F$-statistic of the test for spatial difference; $P, P$-values. Significant $P$-values $(<0.05)$ are highlighted in bold. 


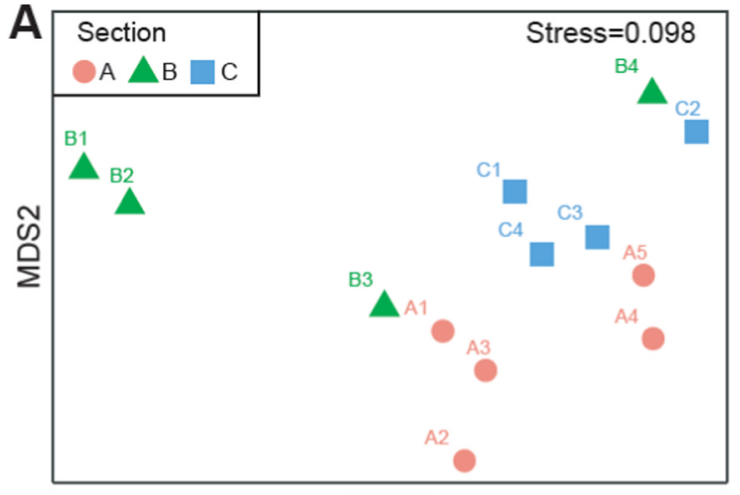

MDS1

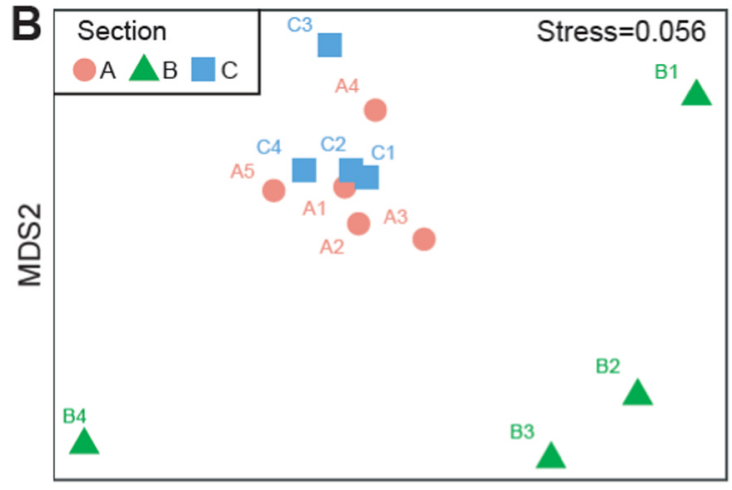

MDS1

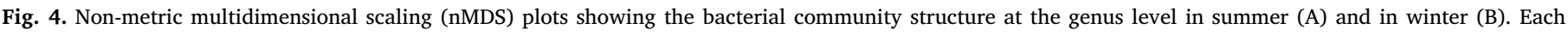
sample label represents site ID.

environmental factors (Fig. 7A). In winter, temperature had an impact on most of the abundant genera (e.g., negative effect on OM43 clade), followed by salinity and water depth, however, the relationship between the genera responsive to spatial difference (i.e. Pelagibacter, unclassified genera in SAR86, Surface 2 and Sva0996 marine group) and

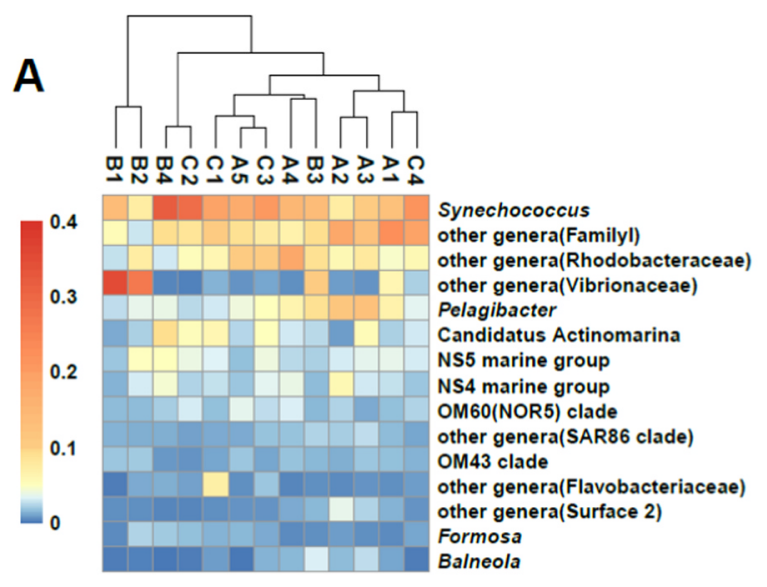

\section{C}
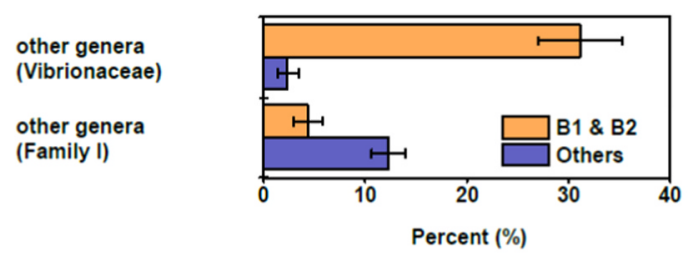

ured environmental factors couldn't be elucidated by network (Fig. 7B). These results reflect that the community dissimilarity in each season, that is the spatial dissimilarity, was only partly explained by the selected environmental variables, and the main reason for the community dissimilarity over space remains undetermined.
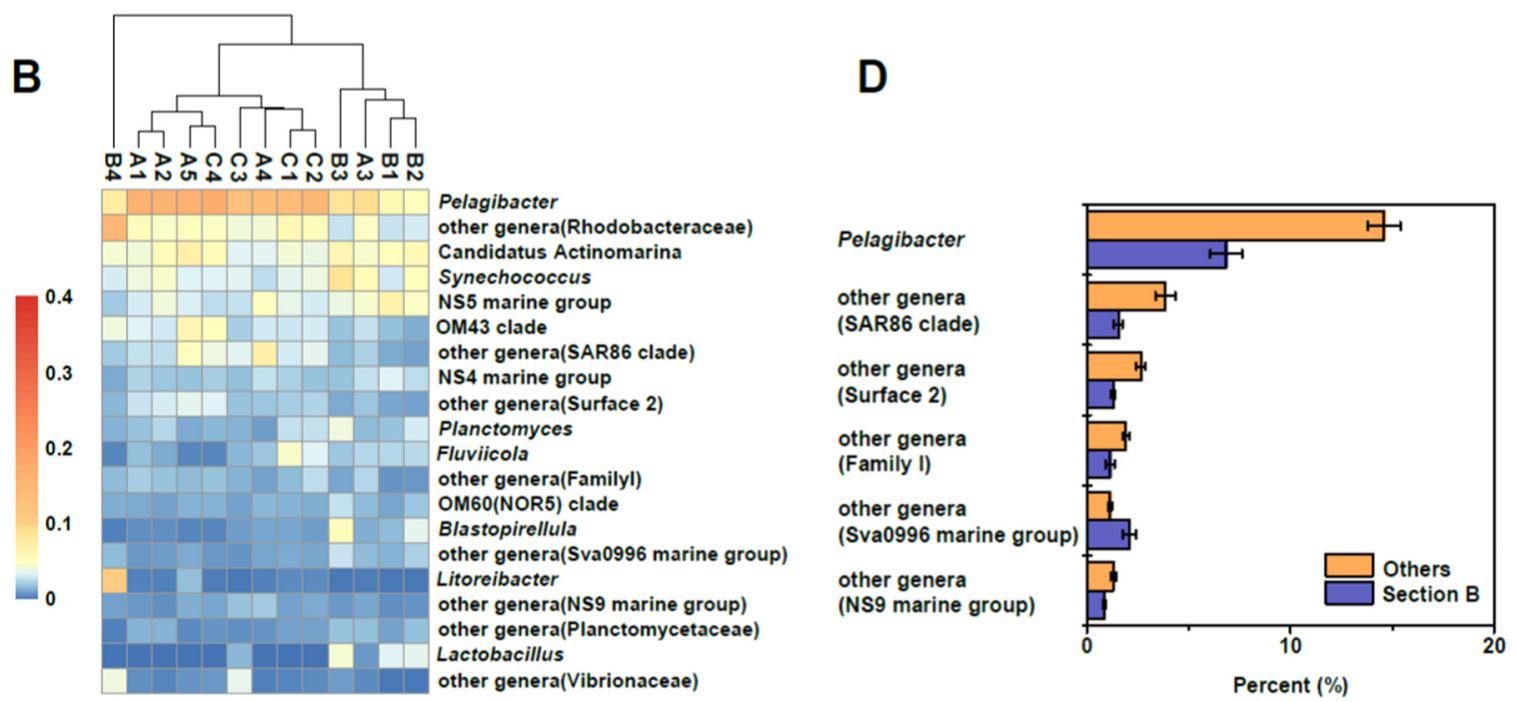

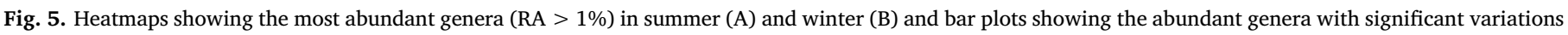
(Mann-Whitney $U$ test: $P<0.05$ ) between different areas in summer (C) and winter (D). 


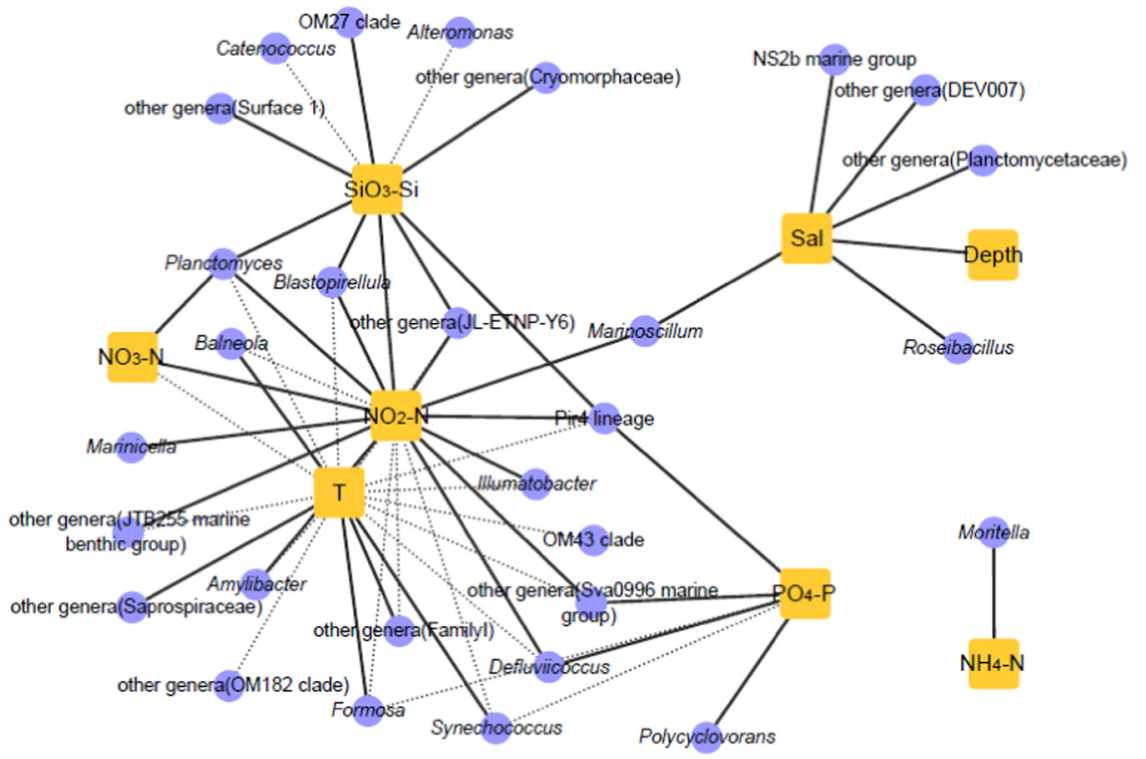

Fig. 6. Association networks showing strong correlations $(\mathrm{r}<-0.6$ or $>0.6)$ between the most common genera (the cumulative percentage of sequences was no less than $90 \%$ ) and environmental factors or between pairs of environmental for two seasons. Each node represents a genus (blue circle) or an environmental factor (yellow square), while each edge represents the interaction between them. Solid line represents positive correlation, and dash line represents negative correlation.

\section{A}

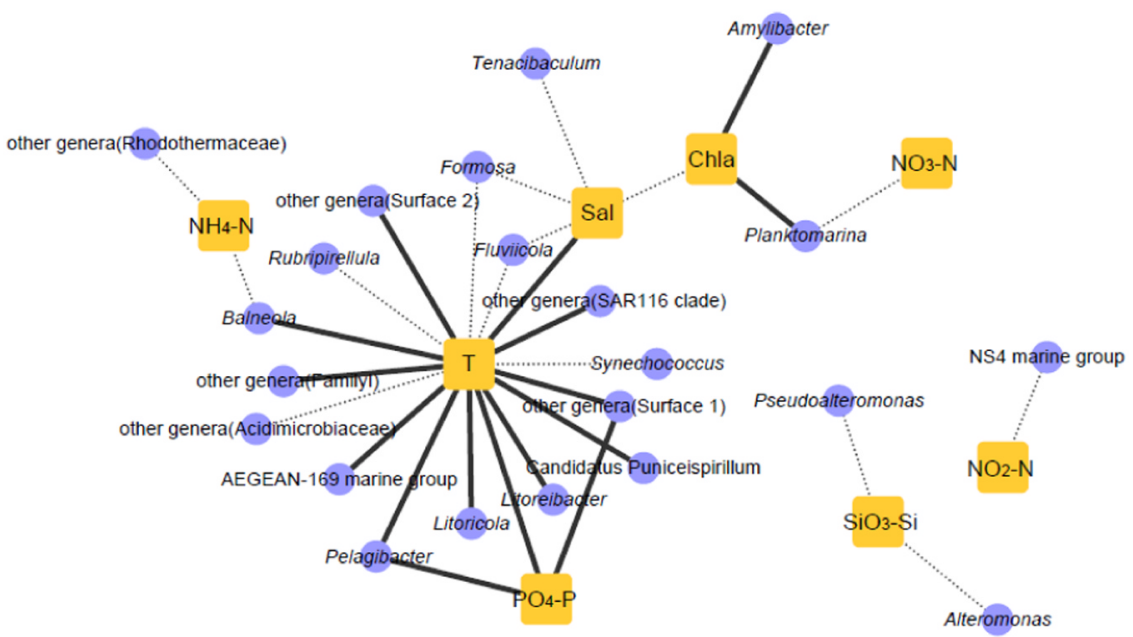

B other genera(flavobacteriaceae)

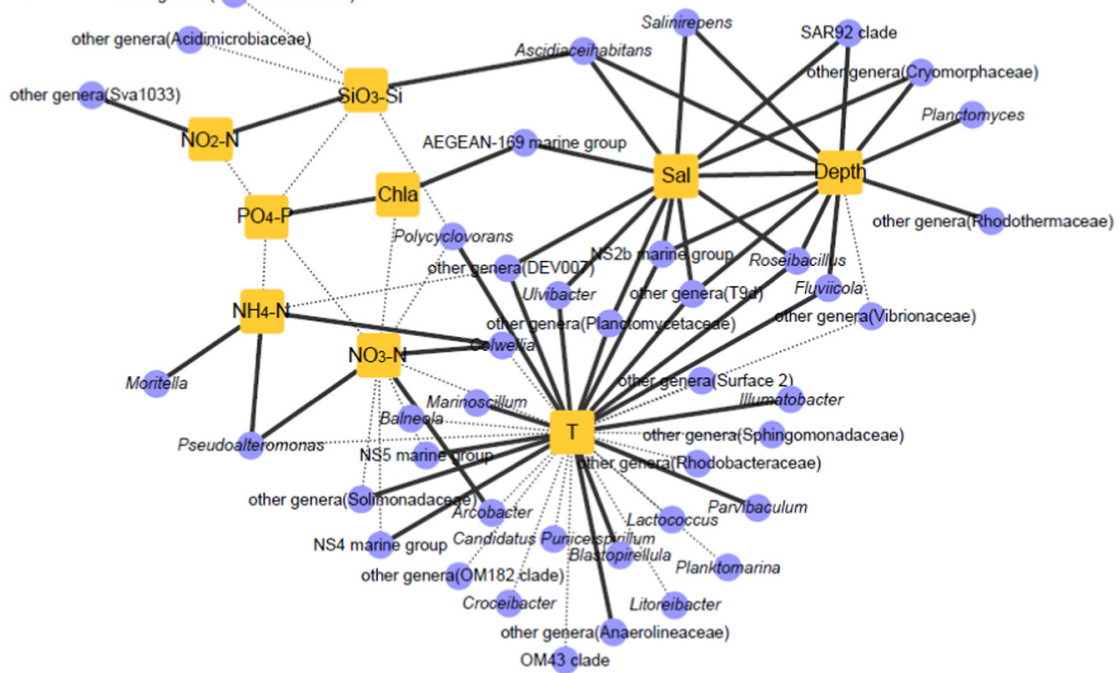

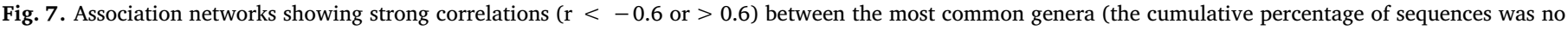
less than 90\%) and environmental factors or between pairs of environmental factors in summer (A) and winter (B). See Fig. 6 for graphical attributes. 


\section{Discussion}

\subsection{The spatiotemporal variations of hydrodynamic features and physicochemical conditions}

In contrast to terrestrial environments, the marine environment is more complicated that the dispersion and movement of populations will be driven by hydrography (Gilbert et al., 2012). The Bohai Strait is strongly influenced by the shifting patterns of the Bohai circulation and the YSWC (Fig. S1, Supporting Information). In summer, when southeasterly winds prevail, Yellow Sea water enters the Bohai Sea through the northern BS and turns counterclockwise when converging with water from the central Bohai Sea before exiting through the southern BS (Guan, 1994; Fang et al., 2000; Hu et al., 2016) (Fig. S1, Supporting Information). The water column in the Bohai Strait is highly stratified during summer and the hydrodynamics are relatively weak, therefore the physical features only differed slightly over the entire BS except for the northeastern area which interacts more with Yellow Sea water (Table 1, Fig. S2, Supporting Information). In contrast, the hydrodynamics intensify during winter (Bi et al., 2011). When northerly winds prevail, the YSWC, which is characterized by high temperature and salinity, intrudes into the northern BS from the Yellow Sea and continues to flow westward, while the coastal currents, with diluted water, flow out from the southern BS (Mask et al., 1998; Guo et al., 2016; Fang et al., 2000) (Fig. S1, Supporting Information). As a result, the hydrological features varied greatly between the northern and southern BS in winter, and the temperature and salinity of surface waters were significantly higher (about $4^{\circ} \mathrm{C}$ and $3 \mathrm{psu}$ ) in the northern $\mathrm{BS}$ than in the southern part. The drastically changing hydrodynamic features that control the dispersal rates of microbes at the regional scale, are likely to affect the biogeography of bacteria in the Bohai Strait.

\subsection{Variations of bacterial community diversity and taxonomic composition in response to environmental changes}

The bacterial communities exhibited significant differences in taxonomic composition and diversity both between seasons and spatially within the Bohai Strait. The alpha diversity estimators of bacterial communities were significantly higher in winter than in summer, especially the Shannon diversity and evenness $(P<0.001)$. Previous studies have shown a similar result that higher values for community richness or diversity were observed in winter and lower values in summer (Gilbert et al., 2009, 2010a, 2010b, 2012; Xia et al., 2015). Shannon evenness describes the distribution of individuals over species or of bacterial groups within the community, while Shannon diversity takes both the richness and evenness into account (Heip et al., 1998; Tam et al., 2001). Both parameters can reflect the equitability of each taxon in the community. The lowered bacterial diversity in the Bohai Strait in summer may be due to unfavorable conditions for most species, such as nutrient limitation caused by stratification, increased competition for limited resources, and predation pressures in surface water during summer. In contrast, the strong wind mixing, surface cooling, and intense intrusion of the YSWC in winter made the water column more homogenized. This provided more favorable conditions for the growth of most bacterial species (Mask et al., 1998; Hainbucher et al., 2004) and resulted in the increased diversity and evenness of bacterial communities in surface water.

The community heterogeneity in taxonomic composition may also be an important response to the changing environment. We chose those bacterial taxa with significant seasonal or spatial variations for further analysis and discussion, because they were the determinants of community variation and were highly responsive to the changing environment. Network analysis determined the bacterial taxa that interacted closely with the measured environmental factors and revealed how they may respond. It was suggested that the measured environmental factors influenced only a few bacterial taxa, whereas most of the highly responsive taxa to environmental changes (Figs. 3 and 5C, D) did not show clear correlations with the measured environmental factors (Figs. 6 and 7).

\subsubsection{The seasonal variation of bacterial communities is mostly controlled} by temperature and nutrient level

BIOENV revealed that among the measured environmental factors, the seasonal shift of bacterial communities in the Bohai Strait was primarily influenced by temperature followed by nutrient concentrations (Table S2). Among the most important responders to seasonal changes, Synechococcus and unclassified genera within Family I were obviously more abundant (3.9 times and 6.6 times) in summer than in winter (Fig. 3). They showed a strong positive correlation with water temperature and a negative correlation with concentrations of $\mathrm{NO}_{2}-\mathrm{N}$ and $\mathrm{PO}_{4}$-P (Fig. 6). Synechococcus are abundant photosynthetic bacteria in the surface ocean and contribute to a substantial proportion of global primary productivity (Flombaum et al., 2013; Pittera et al., 2014). They have higher growth rates and abundances in warmer months associated with temperature, light and nutrient level (Agawin et al., 1998; Jiao et al., 2006). RA of Synechococcus in the Bohai Strait was negatively correlated with concentrations of $\mathrm{NO}_{2}-\mathrm{N}$ and $\mathrm{PO}_{4}-\mathrm{P}$ and positively correlated with temperature, because low temperature was the primary factor limiting their growth, rather than low nutrient level (Chiang et al., 2002; Jiao et al., 2005). Adaptation mechanisms (e.g. excretion of carbon) reduces their dependence on nitrogen and phosphorus availability in the ocean environment (Kretz et al., 2015; Lopez et al., 2016). Additionally, growth inhibition of Synechococcus has been reported at relatively high DIN levels ( $>8 \mu \mathrm{M}$ ) (Agawin et al., 2000). By this criterion, the average DIN concentration in the Bohai Strait in winter was above the level likely to inhibit growth and therefore likely contributed to the decrease of Synechococcus abundance in winter. In contrast, Planctomyces were more abundant in winter than in summer, which may relate to the increased level of inorganic nutrients $\left(\mathrm{NO}_{3}-\mathrm{N}\right.$ and $\mathrm{SiO}_{3}-\mathrm{Si}$ ) and the lower temperature (Fig. 6). This reflects that temperature and nutrient availability have strong effects on microbialmediated processes (Nedwell and Rutter, 1994; Fuhrman et al., 2008; Andersson et al., 2010; Gilbert et al., 2012).

With the exception of Planctomyces, most of the genera that were highly responsive to seasonal changes and dominated in winter were oligotrophic taxa (e.g. genera within SAR11, which included Pelagibacter and unclassified genera in Surface Group 2, unclassified genera within SAR86, and the OM43 clade). Among them, the OM43 clade became more abundant in winter, showing an association with the dramatic decrease of temperature (Fig. 6). The other taxa did not exhibit clear relationships with the measured environmental factors. Nonetheless, almost each of them displayed a clear spatial heterogeneity or patchiness in keeping with the taxonomic patchiness of the communities.

4.2.2. The spatial heterogeneity of bacterial communities implies local resource differences and niche partitioning

The spatial heterogeneity, or patchiness, of bacterial communities in the Bohai Strait was also significant between seasons. The local taxonomic patches were separated by tens of kilometers, which is comparable to the size reported in oligotrophic ocean, supporting the view that factors ultimately shaping assemblage composition are localized at spatial scales between a few kilometers and $\sim 50 \mathrm{~km}$ (Hewson et al., 2006). The patchiness of community composition implies that the distribution of resources, grazers or other bacteria has provided conditions that allow specific taxa to dominate.

Compared with transects A and C, transect B had quite different bacterial community composition in winter. RAs of SAR11 clade (Pelagibacter and unclassified genera of Surface 2) and SAR86 clade decreased significantly in transect B (mainly at sites B1-B3), accompanied by the increase of unclassified genera in Sva0996 marine group 
(Fig. 5B, D). Bacteria of the SAR11 clade are chemoheterotrophic and constitute up to half of the total microbial community in the oxygenrich surface ocean (Morris et al., 2002; Tsementzi et al., 2016). They are deemed as earth's most abundant organisms by adapting to the nutrientlimiting conditions of the open ocean and anoxic conditions in oxygen minimum zones (Giovannoni, 2017; Tsementzi et al., 2016). Sva0996 marine group is an actinobacterial group that has been detected in both marine sediment and water column habitats. Very little is known about the Sva0996 marine group, except its ability to assimilate phytoplankton-derived dissolved protein and involvement in cycling dissolved organic nitrogen in the ocean (Orsi et al., 2016). The decrease of the oligotrophic populations and the simultaneous increase of Sva0996 marine group could suggest a sufficient supply of organic nutrients in this region. Moreover, Planctomyces peaked at sites B3 and B2 in the middle BS during winter (Fig. 7B). This genus was reported to be present in the microbial biofilm community of macroalgae and can dominate particle-attached bacterial assemblages (Lage and Bondoso, 2014). Sites B2 and B3 were located just within the main area of brown algae productivity (e.g. Laminaria spp., Sargassum spp.) in the Bohai Sea and the Yellow Sea. Although the maximum chlorophyll $a$ concentration was observed in the Yellow Sea region (Fig. S2, Supporting Information), the value at site B3 was higher than its immediate surroundings, potentially suggesting a benthic contribution. Therefore, we infer that the increased Planctomyces population in the middle of the study area resulted from the high production of benthic or drifting macroalgae and associated algae-derived organic matter (OM).

In summer, sites B1 and B2 were distinct for containing an abundance of unclassified genera of Vibrionaceae and less unclassified genera in Family I. It has previously been reported in a study of the western English Channel that the family Vibrionaceae bloomed in summer as a result of the presence of eukaryotes (Gilbert et al., 2012). The family Vibrionaceae is routinely found in all ocean environments and contains a number of important pathogenic, commensal, and mutualist species (Thompson et al., 2004; Thompson and Polz, 2006; Jones et al., 2007). Some Vibrionaceae populations attach to planktonic and nektonic organisms, i.e. diatoms, squid and crustacea, for a chitinoclastic activity (Hunt et al., 2008). Nutrients, derived from zooplankton and fishes, can accelerate their growth in seawater (Simidu et al., 1980). The dominance of Vibrionaceae, therefore, can indicate the temporal increase in biomass of fishes, plankton or organic detritus. In our study, unclassified genera within Vibrionaceae were extraordinarily abundant at sites B1 and B2 in summer (Fig. 5A, B), showing no relationship with the measured environmental factors. However, these sites are within the aquaculture zone near the city of Dalian and off the north coast of the Bohai Strait. The abundant animal-derived organic nutrients from Dalian aquaculture could result in the bloom of unclassified genera in Vibrionaceae.

As a result of all the above, the northern and middle parts of transect B were always different from transects A and C, containing functionally distinct dominant bacteria. Those different dominant taxa exhibited niche differentiation in the use of OM substrates. Although we failed to do synchronous measurements of OM types and concentrations, we can infer from our results that OM niche partitioning among bacteria contributed to the patchiness and heterogeneity of the bacterial communities. The patchiness of OM from different sources had a greater impact on bacterial communities than the bacterial dispersal rate, which is closely related to hydrodynamics. However, the impact of hydrodynamics on bacterial communities should not be neglected. The westward flow in the northern BS extended to a larger area when influenced by the intrusion of the YSWC in winter. Consequently, the OM patch that was centered on sites B1 and B2 in summer expanded to site B3 in winter and likely caused the corresponding variation in bacterial communities. Thus, the spread of the current may have influenced the range of OM patches and therefore had an indirect effect on the bacterial community structure.

In addition, several taxa with potential importance in marine carbon cycling had higher abundances in the Bohai Strait, e.g. SAR11 (RA: 12.37\%), OM43 (RA: $2.37 \%$ ) and OM60 (NOR5) (RA: 1.9\%). Their carbon compound specialization might reduce competition and enable them to coexist in large amounts (Rappé et al., 2002; Giovannoni et al., 2008; Yan et al., 2009). OM60 (NOR5) clade is one of the most abundant aerobic anoxygenic phototrophic bacteria in marine environments and their mixotrophic growth provides them with a selective advantage against obligate chemoheterotrophic bacteria (Yan et al., 2009; Spring et al., 2013; Spring, 2014). In our study, bacteria of this clade occurred with a significantly higher RA in summer, but they did not correlate with the measured physicochemical environmental factors (Figs. 3 and 6). This was mainly due to their dependence on light availability, which varied significantly between seasons. OM43 clade is a methylotroph that uses methanol and formaldehyde as carbon sources for energy (Giovannoni et al., 2008; Salcher et al., 2015) and is commonly found at low levels in coastal ecosystems but has been observed to increase in abundance during phytoplankton blooms (Sowell et al., 2011). Our data has revealed a negative correlation between the OM43 clade and water temperature (Fig. 6). Its RA peaked in winter at sites A5, B4 and C4 (Fig. 5C, D) in the south channel where the Bohai Sea Coastal Current (BSCC) dominates (Hu et al., 2016). The BSCC, which flows through the Bohai Bay and the Laizhou Bay successively, is characterized by low salinity and low temperature. The OM43 clade became dominant in this region, suggesting a potential connection with the cold BSCC. However, the mechanism behind the connection needs further study.

\section{Conclusions}

The heterogeneity of environmental conditions (both measured and unmeasured) significantly influenced the spatiotemporal pattern of the bacterial communities in the surface waters of the Bohai Strait. The YSWC provided favorable hydrodynamic conditions and higher nutrient levels, contributing to the significantly higher alpha diversity of bacterial communities in winter than in summer. Some abundant taxa (e.g., Synechococcus, Planctomyces, OM43 clade) showed marked seasonality, which was mostly influenced by the changes of water temperature and nutrient levels. However, the spatial heterogeneity of the bacterial communities can be attributed to factors other than the measured environmental parameters. Some taxa (e.g., Vibrionaceae, Sva0996 marine group, SAR11) exhibited spatial heterogeneity or patchiness most likely related to the patchiness of OM derived from algae or aquaculture organisms, while other taxa, e.g. OM43 clade, showed a correlation with currents. Also, the spread range of currents might have influenced the size of patchiness to a certain degree. In conclusion, our results suggested that $\mathrm{OM}$ niche partitioning among bacterial communities was crucial to the community structure in the Bohai Strait. The relationship between bacterial communities and different sources of $\mathrm{OM}$ substrates, such as algae-derived $\mathrm{OM}$, animal-derived $\mathrm{OM}$, and external organic pollutants, etc., should be further explored. However, our results support the hypothesis that local factors have a greater impact on bacterial community structure than dispersal purely due to hydrodynamics.

\section{Acknowledgements}

We are grateful to Xiangnan Sun and Weiwei Chen in our team for participating in the collection of samples on board. We also thank Dr. Andrew T. Revill from Commonwealth Scientific and Industrial Research Organization (CSIRO), Australia and Dr. Andrew Long from University of Southern California, US, for their valuable comments on the manuscript. This work was supported by the National Basic Research Program (973 Program) of China (No. 2015CB453300), the External Cooperation Program of Chinese Academy of Sciences (No. 133337KYSB20180015), the Key Research Project of Frontier Science of Chinese Academy of Sciences (No. QYZDB-SSW-DQC041), the Strategic Priority Research Program of Chinese Academy of Sciences 
(No. XDA11020403), and the Technology Service Network Plan of Chinese Academy of Sciences (STS, No. ZSYS-006).

\section{Appendix A. Supplementary material}

Supplementary data associated with this article can be found in the online version at doi:10.1016/j.csr.2018.08.009.

\section{References}

Agawin, N.S., Duarte, C.M., Agusti, S., 1998. Growth and abundance of Synechococcus sp. in a Mediterranean Bay: seasonality and relationship with temperature. Mar. Ecol. Prog. Ser. 170, 45-53.

Agawin, N.S., Duarte, C.M., Agustí, S., 2000. Response of Mediterranean Synechococcus growth and loss rates to experimental nutrient inputs. Mar. Ecol. Prog. Ser. 206 97-106.

Andersson, A.F., Riemann, L., Bertilsson, S., 2010. Pyrosequencing reveals contrasting seasonal dynamics of taxa within Baltic Sea bacterioplankton communities. ISME J. 4, 171-181.

Benjamini, Y., Hochberg, Y., 1995. Controlling the false discovery rate: a practical and powerful approach to multiple testing. J. R. Stat. Soc. Ser. B Methodol. 57, 289-300.

Bi, N., Yang, Z., Wang, H., Fan, D., Sun, X., Lei, K., 2011. Seasonal variation of suspendedsediment transport through the southern Bohai Strait. Estuar. Coast Shelf Sci. 93, 239-247.

Bunse, C., Pinhassi, J., 2017. Marine bacterioplankton seasonal succession dynamics. Trends Microbiol.

Chen, C.T.A., 2009. Chemical and physical fronts in the Bohai, Yellow and East China seas. J. Mar. Syst. 78, 394-410.

Cheng, P., Gao, S., Bokuniewicz, H., 2004. Net sediment transport patterns over the Bohai Strait based on grain size trend analysis. Estuar. Coast Shelf Sci. 60, 203-212.

Chiang, K.P., Kuo, M.C., Chang, J., Wang, R.H., Gong, G.C., 2002. Spatial and temporal variation of the Synechococcus population in the East China Sea and its contribution to phytoplankton biomass. Cont. Shelf Res. 22, 3-13.

Edgar, R.C., Haas, B.J., Clemente, J.C., Quince, C., Knight, R., 2011. UCHIME improves sensitivity and speed of chimera detection. Bioinformatics 27, 2194-2200.

Fang, Y., Fang, G.H., Zhang, Q.H., 2000. Numerical simulation and dynamic study of the wintertime circulation of the Bohai Sea. Chin. J. Oceanol. Limnol. 18, 1-9.

Flombaum, P., Gallegos, J.L., Gordillo, R.A., Rincón, J., et al., 2013. Present and future global distributions of the marine cyanobacteria Prochlorococcus and Synechococcus. Proc. Natl. Acad. Sci. USA 110, 9824-9829.

Fuhrman, J.A., Cram, J.A., Needham, D.M., 2015. Marine microbial community dynamics and their ecological interpretation. Nat. Rev. Microbiol. 13, 133-146.

Fuhrman, J.A., Steele, J.A., Hewson, I., Schwalbach, M.S., Brown, M.V., Green, J.L., Brown, J.H., 2008. A latitudinal diversity gradient in planktonic marine bacteria Proc. Natl. Acad. Sci. USA 105, 7774-7778.

Gilbert, J.A., Field, D., Swift, P., Newbold, L., et al., 2009. The seasonal structure of microbial communities in the Western English channel. Environ. Microbiol. 11, 3132-3139.

Gilbert, J.A., Field, D., Swift, P., Thomas, S., et al., 2010a. The taxonomic and functional diversity of microbes at a temperate coastal site: a 'multi-omic' study of seasonal and diel temporal variation. PLoS One 5, e15545.

Gilbert J.A., Somerfield P., Temperton B., Huse S., Joint I., Field D., 2010b. Day-length is central to maintaining consistent seasonal diversity in marine. Nature Precedings.

Gilbert, J.A., Steele, J.A., Caporaso, J.G., Steinbrück, L., et al., 2012. Defining seasonal marine microbial community dynamics. ISME J. 6, 298-308.

Giovannoni, S.J., 2017. SAR11 bacteria: the most abundant plankton in the oceans. Annu. Rev. Mar. Sci. 9, 231-255.

Giovannoni, S.J., Hayakawa, D.H., Tripp, H.J., Stingl, U., et al., 2008. The small genome of an abundant coastal ocean methylotroph. Environ. Microbiol. 10, 1771-1782.

Guan, B.X., 1994. Patterns and Structures of the Currents in Bohai, Huanghai and East China Seas. Oceanology of China seas. Springer, Netherlands, pp. 17-26.

Guo, J., Zhang, H., Cui, T., He, Y., et al., 2016. Remote sensing observations of the winter Yellow Sea Warm Current invasion into the Bohai Sea, China. Adv. Meteorol. 2016, 2016.

Hainbucher, D., Hao, W., Pohlmann, T., Sündermann, J., Feng, S., 2004. Variability of the Bohai Sea circulation based on model calculations. J. Mar. Syst. 44, 153-174.

Heip, C.H., Herman, P.M., Soetaert, K., 1998. Indices of diversity and evenness. Océanis (Paris) 24, 61-88.

Hewson, I., Steele, J.A., Capone, D.G., Fuhrman, J.A., 2006. Temporal and spatial scales of variation in bacterioplankton assemblages of oligotrophic surface waters. Mar. Ecol. Prog. Ser. 311, 67-77.

Hu, N., Huang, P., Liu, J., Shi, X., 2016. Distribution of thallium in the Bohai Sea: implications for hydrodynamic forces and anthropogenic impact. Environ. Earth Sci. 75, $1-12$.

Hunt, D.E., Gevers, D., Vahora, N.M., Polz, M.F., 2008. Conservation of the chitin utilization pathway in the Vibrionaceae. Appl. Environ. Microb. 74, 44-51.

Jiao, N., Yang, Y., Hong, N., Ma, Y., Harada, S., Koshikawa, H., Watanabe, M., 2005. Dynamics of autotrophic picoplankton and heterotrophic bacteria in the East China Sea. Cont. Shelf Res. 25, 1265-1279.

Jiao, N., Zhang, Y., Zeng, Y., 2006. Marine Microbial Ecology 6. Science Press, Beijing, pp. 133.

Jones, B.W., Maruyama, A., Ouverney, C.C., Nishiguchi, M.K., 2007. Spatial and temporal distribution of the Vibrionaceae in coastal waters of Hawaii, Australia, and France. Microb. Ecol. 54, 314-323.

Kretz, C.B., Bell, D.W., Lomas, D.A., Lomas, M.W., Martiny, A.C., 2015. Influence of growth rate on the physiological response of marine Synechococcus to phosphate limitation. Front. Microbiol. 6.

Lage, O.M., Bondoso, J., 2014. Planctomycetes and macroalgae: a striking association. Front. Microbiol. 5, 133-141.

Li, Y., Wolanski, E., Zhang, H., 2015. What processes control the net currents through shallow straits? A review with application to the Bohai Strait, China. Estuar. Coast Shelf Sci. 158, 1-11.

Lindh, M.V., Sjöstedt, J., Andersson, A.F., Baltar, F., et al., 2015. Disentangling seasonal bacterioplankton population dynamics by high-frequency sampling. Environ. Microbiol. 17, 2459-2476.

Lindh, M.V., Sjöstedt, J., Ekstam, B., Casini, M., et al., 2017. Metapopulation theory identifies biogeographical patterns among core and satellite marine bacteria scaling from tens to thousands of kilometers. Environ. Microbiol. 19, 1222-1236.

Lindström, E.S., Langenheder, S., 2012. Local and regional factors influencing bacterial community assembly. Environ. Microbiol. Rep. 4, 1-9.

Liu, D., Li, X., Emeis, K.C., Wang, Y., Richard, P., 2015. Distribution and sources of organic matter in surface sediments of Bohai Sea near the Yellow River Estuary, China. Estuar. Coast Shelf Sci. 165, 128-136.

Lopez, J.S., Garcia, N.S., Talmy, D., Martiny, A.C., 2016. Diel variability in the elemental composition of the marine cyanobacterium Synechococcus. J. Plankton Res. fbv120.

Martiny, J.B.H., Bohannan, B.J., Brown, J.H., Colwell, R.K., et al., 2006. Microbial biogeography: putting microorganisms on the map. Nat. Rev. Microbiol. 4, 102-112.

Mask, A.C., O'Brien, J.J., Preller, R., 1998. Wind-driven effects on the Yellow Sea Warm Current. J. Geophys. Res. 103, 30713-30729.

Morris, R.M., Rappé, M.S., Connon, S.A., Vergin, K.L., Siebold, W.A., Carlson, C.A., Giovannoni, S.J., 2002. SAR11 clade dominates ocean surface bacterioplankton communities. Nature 420, 806-810.

Nedwell, D.B., Rutter, M., 1994. Influence of temperature on growth rate and competition between two psychrotolerant Antarctic bacteria: low temperature diminishes affinity for substrate uptake. Appl. Environ. Microbiol. 60, 1984-1992.

Orsi, W.D., Smith, J.M., Liu, S., Liu, Z., et al., 2016. Diverse, uncultivated bacteria and archaea underlying the cycling of dissolved protein in the ocean. ISME J. 1-16.

Pittera, J., Humily, F., Thorel, M., Grulois, D., Garczarek, L., Six, C., 2014. Connecting thermal physiology and latitudinal niche partitioning in marine Synechococcus. ISME J. 8, 1221-1236.

R Core Team, 2015. R: a language and environment for statistical computing. R Foundation for Statistical Computing, Vienna. 〈www.R-project.org/ $\rangle$.

Rappé, M.S., Connon, S.A., Vergin, K.L., Giovannoni, S.J., 2002. Cultivation of the ubiquitous SAR11 marine bacterioplankton clade. Nature 418, 630-633.

Salcher, M.M., Neuenschwander, S.M., Posch, T., Pernthaler, J., 2015. The ecology of pelagic freshwater methylotrophs assessed by a high-resolution monitoring and isolation campaign. ISME J. 9, 2442-2453.

Schloss, P.D., Westcott, S.L., Ryabin, T., Hall, J.R., et al., 2009. Introducing mothur: opensource, platform-independent, community-supported software for describing and comparing microbial communities. Appl. Environ. Microbiol. 75, 7537-7541.

Shannon, P., 2003. Cytoscape: a software environment for integrated models of biomolecular interaction networks. Genome Res. 13, 2498-2504.

Simidu, U., Taga, N., Colwell, R.R., Schwarz, J.R., 1980. Heterotrophic bacterial flora of the seawater from the Nansei Shoto (Ryukyu Retto) area. Bull. Jpn Soc. Sci. Fish. 46, 505-510.

Sowell, S.M., Abraham, P.E., Shah, M., Verberkmoes, N.C., Smith, D.P., Barofsky, D.F., Giovannoni, S.J., 2011. Environmental proteomics of microbial plankton in a highly productive coastal upwelling system. ISME J. 5, 856-865.

Spring, S., 2014. Function and evolution of the sox multienzyme complex in the marine gammaproteobacterium Congregibacter litoralis. ISRN Microbiol. 2014.

Spring, S., Riedel, T., Spröer, C., Yan, S., Harder, J., Fuchs, B.M., 2013. Taxonomy and evolution of bacteriochlorophyll $a$-containing members of the OM60/NOR5 clade of marine gammaproteobacteria: description of Luminiphilus syltensisgen. nov., sp. nov., reclassification of Haliea rubra as Pseudohaliea rubra gen. nov., comb. nov., and emendation of Chromatocurvus halotolerans. BMC Microbiol. 13, 118.

Tam, L., Derry, A.M., Kevan, P.G., Trevors, J.T., 2001. Functional diversity and community structure of microorganisms in rhizosphere and non-rhizosphere Canadian arctic soils. Biodivers. Conserv. 10, 1933-1947.

Thompson, J.R., Polz, M.F., 2006. Dynamics of Vibrio populations and their role in environmental nutrient cycling. In: Thompson, F.L., Austin, B., Swings, J. (Eds.), The Biology of Vibrios. ASM Press, Washington DC, pp. 190-203.

Thompson, J.R., Randa, M.A., Marcelino, L.A., Tomita-Mitchell, A., Lim, E., Polz, M.F., 2004. Diversity and dynamics of a North Atlantic coastal Vibrio community. Appl. Environ. Microb. 70, 4103-4110.

Tsementzi, D., Wu, J., Deutsch, S., Nath, S., et al., 2016. SAR11 bacteria linked to ocean anoxia and nitrogen loss. Nature 536, 179-183.

Wang, C., Wang, Y., Paterson, J.S., Mitchell, J.G., Hu, X., Zhang, H., Sheng, Y., 2016. Macroscale distribution of virioplankton and heterotrophic bacteria in the Bohai Sea. FEMS Microbiol. Ecol. 92, fiw017.

Xia, X., Guo, W., Liu, H., 2015. Dynamics of the bacterial and archaeal communities in the Northern South China Sea revealed by 454 pyrosequencing of the 16S rRNA gene. Deep-Sea Res Pt II: Top. Stud. Oceanogr. 117, 97-107.

Yan, S., Fuchs, B.M., Lenk, S., Harder, J., Wulf, J., Jiao, N., Amann, R., 2009. Biogeography and phylogeny of the NOR5/OM60 clade of Gammaproteobacteria. Syst. Appl. Microbiol. 32, 124-139.

Zhou, J., Wu, L., Deng, Y., Zhi, X., et al., 2011. Reproducibility and quantitation of amplicon sequencing-based detection. ISME J. 5, 1303-1313. 